\title{
Denaturation of Proteins by Urea and Related Substances.
}

\section{By Sir F. Gowland Hopkins, F.R.S.}

'D ENATURATION', though a phenomenon familiar objectively to all who handle proteins, involves a change of state of which the precise nature is yet obscure. The term itself is scarcely capable of adequate definition. It is only certain that native proteins dispersed in water as lyophil colloids suffer, as the result of diverse alterations in their environment, a change which is accompanied by complete loss of solubility in pure water or dilute salt solutions. If under any influence (such as that of dilute acids or alkalis) a protein denatured in this sense is retained in solution, or redispersed after separation, it is then found no longer in the lyophil but in the lyophobe condition. Denaturation thus understood is always antecedent to coagulation or flocculation, these being secondary processes dependent upon conditions which make for instability in suspensoid systems. We are quite ignorant of the nature of any molecular change which may be responsible for, or accompany, this change in the type of dispersion. Evidence suggesting that some intramolecular readjustment does, as a matter of fact, occur will be mentioned immediately.

A special interest is attached to the change of state involved in denaturation because its occurrence appears to be characteristic of the protein molecule when it is intact. It is apparently not undergone by even the most complex of its degradation products ; this circumstance tends to justify the view, based also on other evidence, that the molecular structure of an intact protein has features differing from, or added to, those of a complex polypeptide.

It is well known that in albumins, globulins, and a number of other native proteins in solution, denaturation is induced by heat, by certain forms of radiation, by the action of relatively strong acids and alkalis, by adsorption at surfaces or in films and mechanically by shaking. Such proteins are also denatured when under defined conditions they are precipitated from solution by such agents as alcohol or acetone.

It has recently become known that these diverse methods of denaturation all produce, in addition to the colloidal change, a shift in the relations of sulphur within the protein molecule, such that the denatured product yields, in some cases directly, and in others after treatment with a reducing agent, a reaction characteristic of the thiol group. This is not given by the native proteins. This characteristic happening was first observed by Heffter in 1909, though he did not specially relate it with the events of denaturation. The relation has sinee been more fully established. 1

An influence, seemingly quite different from those already mentioned but resulting in typical denaturation, is exerted by urea (and, as will be immediately indicated, by other related substances) when added in high concentration to native protein solutions.

This phenomenon has received but little attention until recently. So far back, indeed, as 1900, K. Spiro $^{2}$ directed attention to it. His experiments, however were in the main concerned only with the effect of urea and certain other amides and organic bases in preventing the heat coagulation of proteins or in raising their coagulation temperatures.

Anson and Mirsky ${ }^{3}$ have recently pointed out that urea in concentrated solution can denaturate hæmoglobin, egg albumin, and serum albumin, and that it also dissolves the denatured protein. Hsien Wu has devoted several recent papers to a study of denaturation and has observed that some denatured proteins are soluble in urea solutions, while with
Huang he has taken advantage of this circumstance to determine their molecular weight, finding that " denaturation per se does not necessarily involve a change in molecular weight". Dill and Allsburg employed urea. solutions as solvents for a protein insoluble in water. Burk and Greenberg ${ }^{4}$ have used them in order to determine the molecular weights of proteins at their isoelectric point, and to decide whether they are capable of undergoing changes in their state of aggregation with changes of solvent. They found that hæmoglobin and egg albumin are denatured by urea, and that the former has, in urea solutions, only half the molecular weight indicated in aqueous solution. These authors refer incidentally to the circumstance that formamide, urethane, and thiourea act in solution similarly to urea though not so effectively. Owing to their particular aims, the work of the authors quoted has involved the use of urea solutions as denaturants and solvents rather than a study of the conditions and rate of the changes induced by such agencies.

The following preliminary and descriptive account of certain observations of my own (some were made so far back as 1899 , though now extended) will suggest, I think, that the mechanism of this form of denaturation is worthy of close study.

The experiments have dealt with ovalbumin and with serum proteins. It will be convenient to deal first with the former, which has been more fully studied.

\section{Egg Albumin,}

Pure egg albumin, twice recrystallised by the method of Hopkins and Pinkus and its solution afterwards dialysed until wholly free from ammonium sulphate, was the material usually employed. At the end of dialysis, the $p \mathrm{H}$ of such a solution is invariably within the range of $4 \cdot 8 \cdot 4 \cdot 9$.

If in a few cubic centimetres of such a solution urea be dissolved (say $0.1 \mathrm{gm}$. per c.c.; though the amount is unimportant) and the solution evaporated to dryness in a vacuum desiccator at room temperature, the urea may then be extracted from the residue with water, while the protein will be found to be wholly insoluble, forming a cast of the urea crystals which separate on evaporation. The $p \mathrm{H}$ of the mixture may be adjusted from, say, $4 \cdot 0$ to $7 \cdot 0$ without any difference in the result. If the washed protein residue be now ground up with a few small crystals of sodium nitroprusside and a drop or two of weak ammonia added, a deep red-purple colour characteristic of a sulphydryl reaction immediately develops. If ordinary egg-white be diluted, filtered, and similarly treated, it behaves as described whether at its original $p \mathrm{H}(7.5$ to 8.0$)$ or when brought to $p \mathrm{H} 4 \cdot 8$.

The above simple method is a convenient means for deciding whether or not a given substance exerts a denaturing influence upon proteins. Using the pure albumin a number of substances were thus tested. Positive results were given by methyl-, ethyl-, and butyl-urea; by unsymmetrical dimethyland diethyl-urea; by thiourea; by acetamide, formamide, and by urethane. Wholly negative were the effects of symmetrical diethyl-urea, of acetyl-, and methyl-acetyl-urea; of biuret, allantoin, and semicarbazıde; of alanine, phenyl alanine, valine, leucine, and cystein; of benzamide; of creatine, caffeine, and asparagine. Also negative was found to be the effect of a number of other nitrogenous compounds more remote from the active amides. 
Results so obtained are with ovalbumin quite unequivocal. The residue obtained on evaporation is either completely resoluble or the protein is manifestly denatured. When washed free from the denaturant the denatured protein yields a nitroprusside reaction in all cases, while none is given by the solution when the protein residue remains soluble.

Most of the above denaturants are but slightly dissociated in solution, and in other cases adjustment of the $p \mathrm{H}$ to near neutrality has no effect on their behaviour. It is clear that denaturation on these lines does not depend primarily upon the influence of hydrogen or hydroxyl ions.

To some degree at least, relations between constitution and denaturating power would seem to hold. An amide structure is apparently necessary, but in certain relations its activity is lost. Among the ureas, mono-alkyl substitution, or unsymmetrical di-alkyl substitution, leaves the activity qualitatively intact. Symmetrical di-alkyl ureas, on the other hand, are inactive ; one amino group must apparently remain unsubstituted. To judge from the case of acetyl urea, however, mono-acyl substitution removes however, by reducing agents and the colour reaction immediately reappears if the solution be first treated with cyanides (see later). Its behaviour in the denatured protein is the same, therefore, as in cysteine, glutathione, etc.

Since urea exerts not only a denaturating action, but also a dispersive action upon the denaturated protein, the behaviour of an albumin solution, when urea is added to it, will vary in detail not only with the absolute but also with the relative concentrations of the two constituents. The data in the following table will be sufficient to illustrate the observed effects as modified by concentration variations. The strongest protein solution had a $p \mathrm{H}$ of $4 \cdot 9$, which shifted to $5 \cdot 8$ on saturation with urea. The small variations at other concentrations were insufficient to affect the results. +

It will be seen that though denaturation itself is more rapid with the higher concentrations of urea (see below), the dispersive action may prevent or delay the separation of a precipitate or gel which occurs at lower concentrations. Whether gel or precipitate shall result seems to depend essentially

\begin{tabular}{|c|c|c|c|c|c|c|c|}
\hline \multirow{2}{*}{$\begin{array}{l}\text { Concentration } \\
\text { of Original } \\
\text { Protein Solutions } \\
\text { (per cent). }\end{array}$} & \multirow{2}{*}{$\begin{array}{l}\text { Amount of Urea } \\
\text { added. } \\
\text { (per cent } \\
\text { Saturation). }\end{array}$} & \multicolumn{6}{|c|}{ Condition after standing for the intervals given. Temp. $22^{\circ} \mathrm{C}$. } \\
\hline & & Immediately. & $\frac{1}{2}$ Hour. & 1 Hour. & 2 Hours. & 5 Hours. & 20 Hours. \\
\hline \multirow[t]{4}{*}{7} & 100 & No visible & $\longrightarrow$ & Increasing & Viscosity & $\rightarrow$ & Fragile gel.* \\
\hline & 60 & Ditto & Viscous & Gel & Firm gel & . & \\
\hline & 30 & Heavy cloud & Precipitate & . & Heavy ppt. & . & Protein 50 per cent \\
\hline & 15 & $\begin{array}{l}\text { No visible } \\
\text { change }\end{array}$ & .. & . & . & Cloud & Heavy ppt. \\
\hline \multirow[t]{2}{*}{5} & 100 & $\begin{array}{l}\text { No visible } \\
\text { change }\end{array}$ & $\cdots$ & $\cdots$ & $\cdots$ & Viscous & Marked viscosity \\
\hline & $\begin{array}{l}60 \\
30\end{array}$ & $\begin{array}{l}\text { Ditto } \\
\text { Precipitate }\end{array}$ & $\stackrel{\cdots}{\longrightarrow}$ & Increasing & precipitation & $\ddot{\longrightarrow}$ & $\begin{array}{l}\text { Slightly viscous.* } \\
70 \text { per cent of }\end{array}$ \\
\hline \multirow[t]{3}{*}{2} & 100 & $\begin{array}{l}\text { No visible } \\
\text { ehange }\end{array}$ & $\cdots$ & $\cdots$ & . & . & Viscous. \\
\hline & 60 & Ditto & $\cdots$ & $\cdots$ & Clond & $\cdots$ & Dofinito \\
\hline & 30 & Ditto & $\cdots$ & $\cdots$ & Cloud & $\cdots$ & $\begin{array}{l}\text { Definite precipi- } \\
\text { tate. }\end{array}$ \\
\hline
\end{tabular}

* On longer standing firm gels.

the activity. In biuret, allantoin, and semicarbazide activity is also lost. Acid amides (acetamide and formamide) are active, but all amino acids tried were without effect, and likewise asparagin. Noteworthy is the activity of urethane. Bases of the type of creatin or caffeine are inactive.

More detailed aspects of the events involved in denaturation on these lines are to be observed in solution. If a solution of the pure protein is fully saturated with urea ( $1 \mathrm{gm}$. per c.c.) at room temperature, it will be found to give a well-marked nitroprusside reaction immediately. Even before the solution has recovered from the depression of temperature due to the solution of the urea the colour reaction is marked. By the time that room temperature is reached it becomes, in the case of moderately high concentrations of protein (4-5 per cent) intense. It can be observed to increase during the following half-hour or so.* The establishment of a reactive thiol group in the protein molecule is thus a rapid process, and quantitative evidence of the simultaneous occurrence of a colloidal change will be given later.

If the urea-protein solution is exposed to the air, the thiol group is slowly oxidised. It is restored,

* To observe the full colour, relatively high concentrations of the nitroprusside should be used. Twenty to thirty milligrams of the solid, for example, dissolved in 5 c.c. of the solution. It is then made alkaline with ammonia. on the rate of separation. It may be said that an identical experiment was simultaneously carried out at $37^{\circ} \mathrm{C}$. with little difference in the results save that the gel formation was somewhat faster. Needless to say, any considerable modifications in the concentrations will affect the time relations as given in the above table.

Rapid gel formation can be observed in the case of still stronger albumin solutions and an easy demonstration of the potency of urea as a denaturant is so obtained. If 5 c.c. of undiluted egg-white, which has been first whipped to destroy the membranes and squeezed through muslin, be placed in a test tube and $5 \mathrm{gm}$. or a little less of urea, finely powdered to facilitate solution in the viscous material, be added, the mixture will begin to gelatinise almost as soon as the urea has dissolved. In fifteen minutes or less at room temperature a firm gel is obtained of which a

$\dagger$ Throughout this notice the concentrations of urea, because they are generally so high, are for convenience reported not in terms of molarity but as percentages of complete saturation at $17^{\circ} \mathrm{C}$. (1 gm per c.c.). The results can thus be reproduced without reference to volume changes consequent upon adding varying amounts of urea to the protein solutions. The concentrations of albumin referred to are those of the original solution; those actually present in the ureaprotein mixtures vary therefore with the amount of urea added. It will be found that all essential conclusions are unaffected by thi circumstance; the observations upon which they are based bein comparative. The actual concentration of protein in a solution saturated with urea is given approximately by multiplying that of the original solution by 0.55 , and in a solution 60 per cent saturated by 0.70 
portion, if soaked in a solution of sodium nitroprusside, will develop on its surface a strong purple colour.

The gels, which result from the denaturation of the pure albumin, display many characters of interest. Though eontaining so high a concentration of urea, they are optically completely homogeneous and transparent, resembling in appearance pure silica gels. When treated with successive quantities of water until the urea has wholly diffused out of their structure they become slightly opaque, but they display great resistance to sol formation. When they are heated with excess of water the amount of protein found in the sol phase is, no matter what the temperature, negligibly small. Remarkable is the behaviour of an original gel, still containing the urea, when alternately cooled and warmed. If the flask or testtube containing such a gel be placed on ice, its mass becomes pervaded with silky crystals of urea. If it now be allowed to return to room temperature or even if it be rapidly warmed to higher temperatures, it completely regains its homogeneous transparent appearance, and in the case of a well-formed gel without displaying at any moment the least sign of increased fluidity. The vessel containing it can be placed in a boiling water bath without producing any effect upon its visible characters. Gels formed originally within certain ranges of protein or urea concentration may require to be cooled to a degree or two below $0^{\circ} \mathrm{C}$. before the urea separates as described and should be placed for a few moments in an ice-salt freezing mixture.

With regard to the effect of such internal crystal formation upon the ultimate structure of gels, Moran and Hardy have studied what is clearly a somewhat different case, namely, the formation and disappearance of ice crystals in aqueous gelatin gels when respectively frozen and thawed. These authors discuss the effect of the crystal formation upon the ultimate gel structure. Hardy found, though only in the case of gels much more concentrated than those dealt with here (20 per cent gelatin and upwards), that the capacity of the gel for re-adsorbing water is so great that after thawing, the spaces occupied by the ice crystals vanish " almost entirely" though the collapsed walls of such spaces do not join together. With lower concentrations of gelatin the final result is an open sponge. Hardy also found that the gel, while originally singly refractive, became doubly refractive after freezing and thawing. Evidence for such effects upon the gel structure has proved difficult to obtain in the case of the urea-protein gels by ordinary microscopic study, with or without polarised light. Doubtless a more highly developed technique may be necessary for the purpose. No ice crystals are associated with the urea crystals: separation of the latter within the gel will commonly occur at temperatures somewhat above $0^{\circ}$ C. A study of these urea-protein systems may, I think, prove important with respect to gel structure.

When in any circumstances the denatured protein separates not as a gel but as a precipitate, it is found to be insoluble in hydrochloric acid of any strength, and is only very slowly dispersed in alkalis. On the other hand, in a saturated solution of urea it is dispersed to a clear sol.

If an albumin solution, after admixture with urea in effective quantities, be diluted or dialysed at any stage before a precipitate or gel has formed spontaneously, the denatured product is precipitated. A precipitate is obtained almost immediately after the urea has been added, but the amount becomes, of course, greater with the progress of denaturation. Precipitation does not occur, however, if the $p \mathrm{H}$ of the mixed solution is appreciably greater than $6 \cdot 0$. When thoroughly dialysed solutions of the crystallised albumin are employed as in most of the experiments under discussion, one effect of adding pure urea in the amounts employed is to shift the $p H$ from 4.8 to $\pm 5 \cdot 8 . \pm$ In these circumstances the precipitation of the denaturated albumin on ten-fold dilution of the solution or on dialysis is nearly complete. If, how ever, before or after the addition of urea the $p H$ is brought to 6.5 or higher by the addition of minute quantities of alkali, no precipitation occurs. If, on the other hand, such a solution be dialysed until all urea is removed (the $p \mathrm{H}$ being thereby somewhat reduced) the denatured protein present is found to be in typical suspensoid or lyophobe solution. The urea-free solution is precipitated by salts in minute concentration and the negatively charged particles obey the rule of Hardy. Needless to say, the charge may be reversed by shifting the $p \mathrm{H}$ to the acid side of the isoelectric point. It may be mentioned that when weak solutions of albumin containing high concentrations of urea are allowed to stand for three or four days some form of stabilisation may be observed. Clear suspensoid solutions may then be obtained on dialysis when the $p \mathbf{H}$ of the original mixture was less than $6 \cdot 0$. The particles then carry a positive charge.

¥ Such a change in $p \mathrm{H}$ seems in the circumstances to be unduly great. All estimations were made with the quinhydrone electrode. My colleague, Dr. M. Dixon, has since suggested to me that a chemical action of urea upon the quinhydrone might lead to error. With th hydrogen elctrode, however, a shift of the same order is observed. The values obtained with the quinhydrone are perhaps 0.2 of a $p \mathrm{H}$ unit too high.

1 L. J. Harris, Proc. Roy. Soc., B 94, 425, 1923 ; F. G. Hopkins, Bioch. Jour., 19, $807,1925$.

2 Zeit. f. Physiol. Chem., 30, 182

s Jour. Gen. Physiol., 13, 123; 1929.

\section{(To be continued.)}

\section{Norwegian Contributions to the Geology of Spitsbergen.*}

DURING every year between 1906 and 1926, Norwegian State-aided expeditions have been at work in western and central Spitsbergen. Of nineteen out of the twenty-one expeditions the geologist, Adolf Hoel, was the leader or joint-leader, and he has prepared, as the first of the long series of Skrifter on Spitsbergen or Svalbard, an account of the whole series with summaries of the routes and the work undertaken, maps showing the journeys and the areas surveyed, and appendices on the topographic and hydrographic work.

This memoir will be a great aid to those using the * Det Kongelige Departement for Handel, Sjøfart Industri, Handverk og Fiskeri. Norges Svalbard- og Ishavs-Undersokelser. Skrifter om Svalbard, og Ishavet. Nr. 1, 19-24. (Oslo: Jacob Dybwad.) 10, $3,2.50,4,15,3$, and $3.50 \mathrm{Kr}$.

No. 3174 , VoL. 1261 special reports, of which six new contributions are issued along with it. They make an important addition to the geology of Spitsbergen. Hans Trebold has written two memoirs on the Mesozoic rocks, and shows that the Jurassic is represented by the Upper Lias and all the stages from the Lower Callovian to the Upper Volga Beds, which are equivalent to the Purbeck and Lower Wealden of England and the Tithonian of Central Europe. The sequence is then continued through the Lower Cretaceous up to the Aptian. This long succession is nearly all marine, though there are two local developments of estuarine or fluviatile beds with land plants. The author carefully discusses the geographical relations of these beds and the nature of their faunas. He discusses the 